\title{
Surf Tourism and Sustainable Development in Indo-Pacific Islands. I. The Industry and the Islands
}

\author{
Ralf Buckley \\ International Centre for Ecotourism Research, School of Environmental \\ \& Applied Sciences, Griffith University, PMB 50, Gold Coast Mail Centre \\ Southport Qld 9726, Australia
}

Commercial surf tourism is recent in origin but is now a significant component of the worldwide adventure tourism sector. There are over 10 million surfers worldwide and a third of these are cash-rich, time-poor and hence potential tour clients. Most travelling surfers visit mainland destinations and are not distinguished from other tourists. Specialist surfing boat charters and lodges are most prevalent in Indo-Pacific islands. In the smaller reefislands, growth in tourism carries risks to drinking water and subsistence fisheries. There risks are easily overcome, but only if appropriate waste and sewage management technologies are installed. In the larger rock islands, nature and adventure tourism may provide an economic alternative to logging and plantation agriculture. Cultural impacts can occur in either type of island. As with most types of adventure tourism, the commercial surf tourism industry in the Indo-Pacific is strongly linked to the clothing, fashion and entertainment industries, and marketed through specialist surfing magazines and surfing media. From a tourism development perspective, the trend is towards integrated ocean sports destinations which attract entire families as well as individual surfers. Currently, however, marketing crossovers with other specialist ocean sports such as diving are far smaller than with other boardsports such as snowboarding.

\section{Introduction and Methods}

It is only recently that commercial surf tourism has reached any appreciable economic scale. Currently, however, it is bringing tourism development, with its associated economic, social and environmental costs and benefits, to island communities throughout the Indian and Pacific Oceans. Surf tourism in Indo-Pacific islands provides a striking example of the wave of adventure tourism development which is now sweeping worldwide. In particular, it is almost completely tied to highly specific features of the natural landscape; it is largely disjunct from the cultures of host communities; and it has strong economic links to the global fashion and entertainment industries.

In addition, in many islands, growth in commercial surf tourism quickly tests the limits of recreational capacity, in the particular sense that crowding between commercial clients reduces the value of the experience for the tourists, and hence the potential price available to operators. Surf tourism on small islands hence provides a strong case for managed access to limit both crowding of clients and cultural impacts on host communities. This, however, commonly brings conflicts: between tour operators; between commercial tour clients and 
independent travellers; and in some cases between different factions within host communities.

The commercial surf tourism industry does not seem to have been described previously in the tourism literature. This analysis, therefore, starts with an overview of the history and current structure of the sector, with minimal use of specialist surfing terminology. Information for this review is derived from personal experience in the sector; interviews with commercial surf tour operators and agents; direct observations at surf destinations and on surf tours; surfing and adventure tourism magazines; commercial publications in the surfing industry, such as product catalogues and investment prospectuses; and websites for commercial surf tourism operations. It is an overview from a tourism development perspective and does not attempt to provide a comprehensive history of recreational surfing. Such histories are available in, for example, Bartholomew (1996), Hynd (1991) and Young (1994).

This analysis is presented from the perspective of an environmental scientist working in tourism who is also a surfer with ten years experience. It is an introductory overview intended to demonstrate that surf tourism has become a social phenomenon of sufficient economic, social and environmental significance to justify academic attention. As such it has a strong descriptive and practical focus. One of its aims is to stimulate more detailed analyses of specific destinations. There is apparently no previous academic literature on surf tourism, and reference is hence necessarily made to non-academic sources, and to personal observations over the past decade.

Surf tourism, along with other forms of adventure tourism and outdoor recreation, may also provide opportunities to test established theories of human social behaviour relating to crowding, home-versus-holiday norms, cross-cultural interactions, and peer-group dynamics. These theoretical frameworks, however, are beyond the expertise of the present author, and beyond the scope of this contribution.

The surfing industry is worldwide, but concentrated in particular areas. Commercial surf tourism relies heavily on island nations in the Indian and Pacific Oceans. Many of these islands have relatively small and often aiddependent cash economies grafted onto a traditional social framework and subsistence economy. For these islands, surf tourism has become a significant additional factor influencing economic, social and environmental patterns and processes. Hence, the focus of this analysis is in the Indo-Pacific regions, though instances from other parts of the world are included where relevant.

The islands of the Indo-Pacific region have particular natural and social characteristics which influence their opportunities for sustainable development, and these are summarised as the context for surf tourism specifically. Data are derived from reviews of island economies by multilateral financial institutions and bilateral development assistance (AIDAB, 1991a,b, 1992a-d); interviews with government personnel in the countries concerned, in tourism and environmental portfolios, and their private sector counterparts; personal experience in research and consulting in Indo-Pacific island nations over the past quartercentury; and relevant websites. 


\section{The Surf Tourism Industry}

\section{History and structure}

Only in Hawaii is surfing an ancient tradition. Modern surfing has been in existence for barely half a century, and the now ubiquitous 3-fin foam-and-fibreglass shortboard, known as a thruster, was first ridden in 1981 (Hynd, 1991; Young, 1994). Accessories such as legropes, wetsuits and board covers, and design features such as detachable fins, are even more recent in origin. Sailboards were invented in the 1970s, and kitesurfing not until the 1990s. Commercial surf tourism, as opposed to the independent travelling surfer, has come into prominence only in the last decade. Surfboards of soft plastic construction similar to bodyboards, which have rendered learning to surf largely risk-free and have led to a boom in backpacker surf schools, have become widely available only in the last five years.

There are now estimated to be over 10 million surfers worldwide, increasing at $12-16 \%$ p.a., and surfing is now a multi-billion dollar global industry. Its worldwide value was estimated at over US $\$ 2.5$ billion p.a. in the mid-1990s (Raymond, 1998). There are apparently no published calculations of its total current value. There are perhaps three main components. Sales of surf-branded clothing are dominated by a few large labels and can be estimated from annual reports and associated stock exchange data from major surfwear companies (McKnight, 2002), at around US\$6.3 billion in total (Anon, 2001). Manufacturing of surfboards, wetsuits and accessories is much more diffuse. An average expenditure estimate of \$300-\$500 per surfer per year is not unreasonable, allowing for second-hand sales. Travel costs are most difficult to estimate, especially if local travel from home to beach is included, but are probably similar. Overall, US $\$ 10$ billion p.a. is perhaps not an unreasonable approximation for the current economic scale of the surfing industry, and may be conservative.

In terms of economic statistics, surfing becomes tourism as soon as surfers travel at least $40 \mathrm{~km}$ and stay overnight with surfing as the primary purpose for travel. This may be considered in two components, namely recreational surf travel, and commercial surf tourism. In recreational surf travel, surfers plan their own trips, use their own transport and equipment, and stay in local accommodation or their own tents. Trips may be long or short, local or international, but expenditure per person per day is typically low. Recreational surf travel is as old as surfing itself.

In commercial surf tourism, tour operators plan and package all the logistic aspects of the trip, generally including transport, accommodation and food. Clients bring only boards and personal gear, and pay a predetermined price for the tour, as for any other kind of tour. Commercial surf tours include, e.g. low-budget bus safaris with flexible itineraries; high-budget boat tours with local flexibility but fixed ports and dates; and visits to fixed-site surf camps, lodges and resorts with open or sometimes exclusive access to particularly famous surf breaks. There are also combinations, charter operations, travelling competitions, and freestyle surf film crews.

For purposes of definition, therefore, commercial surf tourism may be considered as purchasable holiday packages where clients travel more than $40 \mathrm{~km}$ from 
home, stay overnight, and intend to devote their active leisure time principally to surfing.

Surf tourism thus has close parallels to other types of adventure tourism. Adventure tourism started with hunting and fishing outfitters over a century ago, and progressed to photo safaris, sport fishing, mountaineering, rockclimbing, and more recently scuba diving, whitewater kayaking, and backcountry skiing and snowboarding. Each of these originated as a private recreational activity, and gradually grew into a component of the tourism industry as individual exponents grew older and either (a) changed to lifestyles with more money but less time, or (b) established businesses as full-time guides and outfitters. In each case, private recreation has grown in parallel with commercial tours, and equipment manufacturers rely on both equally. During the past decade or so, however, there seems to have been a significant social change in the developed Western nations, where young but relatively wealthy urban residents have begun to treat these activities as purchasable holiday experiences rather than individual lifetime skills (Buckley, 2000a). Of course, the two are linked, since relevant skills are needed to enjoy an adventure tourism holiday; even there, however, clients arrive with lower and lower individual experience, expecting higher and higher levels of instruction, assistance and safety from tour guides and operators.

It is not only the growth in 'cash-rich, time-poor' tourists which has fuelled the grow th in adventure tourism, including surf tourism. The increasing numbers of people who take part in these activities, encouraged by clothing advertisements and associated television programmes, has led to considerable crowding at local climbing cliffs, whitewater rivers and surf breaks near Western cities. Those who can afford to do so, therefore, want to travel to high-quality uncrowded sites. At the same time, television programmes, videos and specialist magazines fuel the demand by illustrating these destinations, usually with professional athletes performing in perfect conditions. The number of outdoor sport, recreation and adventure magazines has increased very rapidly in recent years. There are at least a dozen different surfing magazines currently on sale, for example, including those aimed specifically at longboarders, bodyboarders, female surfers and travelling surfers (Google, 2002; Surf Info, 2002). At least one of these magazines (Tracks) has been in production for over 30 years, but many of the more specialised publications are only one or two years old. There are also a number of e-zines devoted to surfing (Google, 2002).

It is only in the last decade or so that the first generation of modern surfers, a generation large enough to support a retail industry, has become sufficiently wealthy to pay for surf charters and surf lodges, and sufficiently busy to prefer a package product to independent travel. About 30\% of the world's surfers are now estimated to be over 30 years old (Raymond, 1998). At the same time, the greatly increased number of surfers in younger generations has crowded well-known surf breaks to the point where these older, cash-rich time-poor surfers are prepared to pay for high-quality, uncrowded waves during their brief holidays. It is these surfers who support the bulk of the more upmarket surf tourism sector, the surf charter boats and island surf lodges and resorts. Clients of these surf tours are by no means all old: many of them are in their 20's and 30's, successful in their trade, business or profession; for others, a surf holiday is an occasional big-ticket expense. With surf charter boats commonly costing around 
US\$100-275 per person per day, or up to US\$2750 for a typical 10-day charter, plus airfares and extras (Atoll Travel, 2002; Great Breaks International, 2002; Indies Trader, 2002; Surf Travel Company, 2002, World Surfaris, 2002), the majority of surfers in their teens and young 20 s are hence unlikely to take part in tours of this type.

To cater for younger surf tourists, a number of companies now offer surf safaris, generally a charter bus which travels along a mainland coastline stopping at well-known surf breaks, with accommodation typically in backpackers' hostels and similar establishments (Surfaris, 2002; Surf Info, 2002). Finally, in popular surfing destinations there are now surf schools with their own minibuses, which sell learn-to-surf classes, including equipment rental, with touring backpackers as a major market (e.g. Surfing Australia, 2002; Surf Info, 2002; Waves Surf School, 2002).

One further component of the surf tourism industry, though relatively small-scale to date, is the construction of artificial indoor wave pools such as those now existing in some Japanese cities. The most recent development in this field is the Swatch ${ }^{\circledR}$ Wave, which is in fact not a wave but a flume, where pumps direct a thin sheet of water at high velocity over a solid wave-shaped structure. Apparently, however, riding the wave-shaped section of this flume, on a special board, requires quite different skills from riding a real wave on a surfboard (Swatch, 2002).

The age structure of the current surfing population worldwide suggests that the demand and ability to pay for surf tours will continue to increase substantially for at least the next two or three decades. In addition, as surfing becomes easier to learn, it seems likely that its popularity will continue to increase in future generations.

\section{Geography}

Except for the wave pools and flumes mentioned above, surfing requires surf, which occurs consistently in only some parts of the globe (Bartholomew, 1996; Surf History, 2002; Surf Info, 2002; Young, 1994). A wide range of factors influence the quality and consistency of surf, including swell height, fetch and wave length; seabed profile and nearshore seafloor shape and structure; tide and wind regimes; and so on. In addition, difficult access, particularly cold water, and lack of information have historically kept surfers away from some areas, even though they may have high-quality surf. These barriers are now becoming less significant as travelling surfers seek out new opportunities. In particular, since surfing itself can commonly involve a significant degree of physical risk, it appears that even older surf tourists may be less concerned than tourists in general in regard to other travel risks, such as tropical diseases or political instability (R. Cameron, pers. comm., 2000).

Many surfers travel within or between the major continental surfing destinations, such as Australia, west-coast USA, south-coast Europe, Brazil and Central America, and South Africa. This travel is generally not differentiated specifically as surf tourism, so its total economic scale and value currently remain unknown. For example, a significant proportion of the younger Japanese and Brazilian visitors to Australia's Gold Coast make the trip specifically to surf (Stone, pers. comm., 1999), and many also buy new surfboards, sometimes several (Hyman, 
pers. comm., 1998). In addition, many visitors to the Gold Coast, including those who do not surf, buy surf clothing and accessories (Billabong, 2002c; Quiksilver, 2002; Rip Curl, 2002), which currently appear to be particularly fashionable in Europe (McKnight, 2002). The township of Jeffrey's Bay in South Africa receives a significant part of its income from surfers who travel there to sample its legendary waves. Coastal townships such as Hossegor in France or Mundaca in Spain are internationally-known surfing locations as well as destinations for domestic beach tourism. The islands of Oahu and Maui in Hawaii, and the coastline around Rio in Brazil, are large-scale international destinations for a wide variety of tourists, and whilst surfers may make up only a small component in proportional terms, their total numbers are sufficient to make a significant economic contribution.

The most clearly differentiated sectors of the surf tourism industry, however, are the relatively recent but rapidly growing boat charters and lodges on the reef-fringed islands of the Pacific and Indian Oceans (Surf Info, 2002). These island reef breaks have been visited for decades by a small number of independent travelling surfers, but access has been difficult and time-consuming, and local transport and accommodation uncertain. As information about these waves has gradually been spread through surf magazines and videos, the surf tourism industry has arisen to supply logistics and expert local knowledge. Initially, the focus was on boat charters, typically for groups of 6 to 12 surfers with no non-surfing passengers on board. The individual boats need only stay in the charter area as long as they have bookings: if the season for good surf lasts only part of the year, they can move elsewhere during the off season. Once tour operators begin to build lodges, however, with year-round staff and maintenance costs, they need a wider market to maintain viable operations year-round. Many of them have therefore begun to offer a range of water sports and other activities that do not require the same skill level as surfing, in order to attract couples and families with some non-surfing members (Blanche, pers. comm., 1998).

Currently, therefore, the principal geographic focus of the specialist surf tourism industry is in the islands of the Indo-Pacific region, with air access as a critical constraint. The world's most widely-known surf is on the North Shore of the island of Oahu in Hawaii. The nearby island of Maui is also world-famous for big-wave windsurfing, kitesurfing and tow-in surfing (Extreme Sports Maui, 2002). Hawaii is a major tourism destination irrespective of surfing, however, with a principal focus on the beach resorts of Waikiki. Surfing, and particularly surf competitions, probably contributes more to the Hawaiian tourist economy as spectator sports than as adventure tourism. Surfers worldwide want to surf in Hawaii, but they do so as part of the mainstream mass tourism industry rather than the specialist surf tourism industry. Crowding and localism are intense, driving many travelling surfers to other destinations. Similar considerations apply for Tahiti. An archetypal South Seas Island destination famous for scenery and black pearl, it also has internationally famous surf breaks such as Teahupoo.

Fiji is famous for the surf resort at Tavarua, and more recently for new resorts at Nagigia, Namotu and Yanuca (Amazing Fiji, 2002; Fiji Escapes, 2002). Western Samoa has two surf resorts on the island of Upolu, Salani and Samoana (Salani Surf Resort, 2002; Sa'Moana Resort, 2002); and a surf safari operator on the island 
of Savaii, Savaii Surfaris. There is also a small surf resort on the island of Tongatapu in Tonga (Ha'atafu Beach Resort, 2002), and a beach resort which advertises surfing (Otuhaka Beach Resort, 2002). For French-speaking surfers, Noumea is a famous South Pacific destination, and Reunion in the Southern Indian Ocean is well-known for the surf break at St Leu (Wannasurf, 2002). Nearby Mauritius also attracts travelling surfers, and further north, the Maldives have become an international surf tourism destination. Other Indian Ocean island destinations such as the Seychelles and the Andaman Islands are also visited by touring surfers, though less well known. The Andaman Islands were apparently first surfed in 1998 (South East Asia Liveaboards, 2002).

\section{Marketing}

Specialist surf tour operators in the Indo-Pacific region market principally though specialist surfing magazines, specialist surf travel agents, and directly via the internet (Atoll Travel, 2002; Surf Info, 2002; World Surfaris, 2002). Some operate at only a single location, whereas others offer tours to a wide variety of different countries and destinations. Some surf lodges and surf charter boats sell their products through many different agents, whereas others have exclusive agency agreements with particular agents in individual countries. Anecdotal evidence suggests that most surf tourists select their preferred destination first, before they search for a tour operator to take them there. Tour operators which offer multiple destinations, in contrast, aim for repeat business, where an individual surfer will take a series of surf holidays to different destinations but using the same operator. Overall patterns of new and repeat business for different destinations and operators have not been analysed, and may well be changing rapidly.

As with most forms of adventure tourism at present, marketing in the surf tourism industry is driven by specialist magazines, and to a lesser extent websites, videos and television programmes. All of these feed off a professional competition circuit supported principally by sponsors. The major sponsors are large international surf clothing companies such as Billabong, Quiksilver and Rip Curl, with total share capitalisation measured in billions of dollars (McKnight, 2002; Quiksilver, 2002; Rip Curl, 2002). Individual professional surfers are sponsored by these and smaller surfwear companies, and also by surfboard and sunglass manufacturers. The major surfwear brands have helped to popularise Indo-Pacific island surfing destinations through marketing campaigns such as 'The Search' (Rip Curl, 2002), 'The Crossing' (Quiksilver, 2002), and 'The Odyssey' which has apparently featured in the July 2002 issue of fashion magazine Vanity Fair (Billabong, 2002a).

There is an international competition circuit, the World Championship Tour (WCT), for the world's top 44 professional surfers, with individual events named after various sponsors. There is also a second-tier world circuit, the World Qualifying Series, which feeds into the WCT. In addition, the major surfwear manufacturers sometimes sponsor individual competitions outside the WCT and WQS, in order to gain additional marketing opportunities. Examples are provided by Quiksilver Airshow (Quiksilver, 2002); and the Billabong Boost (Billabong, 2002b). Unlike WCT and WQS events, which are judged on a wide variety of moves and factors, the Airshow is judged solely on each competitor's 
single most spectacular, difficult and successful aerial manoeuvre. It is not coincidental that aerial manoeuvres, particularly inverted airs, make especially arresting advertisements and television footage. Again, this pattern is commonplace in many of the freestyle and extreme adventure and adrenaline sports.

From a large-scale economic perspective, therefore, surf tourism is a small part of a surfing industry which uses athletes, competitions, sponsorships and entertainment media in order to sell clothing and accessories. From this perspective, sport and adventure, surfing included, have become part of the rag trade (Buckley, 2000a,b); or more broadly, since adventure is also used to sell everything from cars to cigarettes (Trent, 2000), part of the fashion industry. For example, one of the world's first and most-famous surf lodges, Tavarua in Fiji, has recently become a subsidiary of a new and larger corporation, the Tavarua Surf Clothing and Island Resort Company. As regards tourism marketing specifically, there seems to be a strong trend to present every tourism product either as an 'adventure experience' or as 'luxury pampering' - or sometimes, as both simultaneously.

\section{Magazines}

As more and more people worldwide have learned to surf, specialist surfing magazines have increased in number and diversity. The majority of surfing magazines are still aimed at young male surfers, but there are also numerous magazines specifically for bodyboarders, and several for longboarders. Over recent years a number of surfing magazines aimed specifically at female surfers have also started production, with titles such as Wahine, Chick and Surfer Girl. No doubt it is only a matter of time until someone starts a magazine called Mambo Goddess. Chick has now expanded beyond surfing. Major surfwear companies also have separate websites or subsites specifically for female clients (Billabong, 2002c). There is also at least one surf magazine, Surf Adventures, aimed specifically at surf tourists and travelling surfers.

All of these magazines now carry advertisements for surf tours, surf safaris, surf lodges and surf schools as well as surfboards, wetsuits and surfwear. The number of different surf tourism products advertised in surf magazines has increased considerably over recent years. The number of surf tourism products advertised in the mainstream Australian surfing magazine Tracks, for example, has increased steadily during recent decades (Stone, 2000). Most of these advertisements are for surf tours and lodges in Indo-Pacific island destinations. Much of the editorial content of these magazines, including articles, interviews and competition reports, refers to the same destinations; and all of them are illustrated lavishly with professional photographs of near-perfect waves. All of these combine to boost demand for surf tourism products.

At the same time, the major surfwear manufacturers now issue annual products catalogues with an increasing focus on urban female fashion. The year-2000 catalogue from Rip Curl, for example, devoted over half its glossy full-colour pages to clothing and accessories for women, and included a section called 'Urban Edge', with an emphasis on streetwear rather than surfwear. Even in the male clothing sections, the marketing messages are based as much on sex as on surf, though with an approach which is backhanded and humorous rather than blatant. The more blatant approach, however, is used by footwear manufacturer 
Reef®, which sells sandals for surfers. The Reef advertisements have retained a remarkably uniform theme and pictorial design over many years, to the point where they have become legendary amongst the surfing community.

\section{Crossovers and links}

Many surfers are also snowboarders or skateboarders, and there is a degree of cross-marketing between these sports. Companies such as Quiksilver make snowboard clothing as well as surfwear, and sponsor events where participants compete both in the surf and on the slopes (Quiksilver, 2002). Similarly, some tour operators run trips to the snow as well as to surf destinations (Go Tours, 2002). Snowboard tours, and sometimes also snowboard videos, are often advertised in surfing magazines, and vice versa. A similar cross-over occurs with skateboarding. There seems to be relatively little advertising crossover, however, between surfing and other surf sports such as bodyboarding, surfskis, sailboarding or surf lifesaving, each of which has its own specialist magazines. A few individuals may be involved in many of these individual sports, but a more common pattern is for devotees of each to look down on the others.

One interesting and somewhat surprising new trend is that some surfing magazines have begun to carry occasional advertisements for golfing equipment. This seems to have happened because one or two of the top professional surfers began to play golf, and others followed suit, in a graphic demonstration of how sports are influenced by fashion. Surfers in general, however, do not seem to have taken to golf in significant numbers, so this crossover remains small. This contrasts with the ski industry, which now has a very high crossover with golf. This has reached the point where many US ski corporations have been renamed as ski and golf corporations during recent years, and some of the larger ski equipment retailers have expanded to become ski and golf equipment retailers. Examples are provided by the Telluride Ski and Golf Co. (Telski, 2002), and the Colorado Ski and Golf retail chain in Denver Colorado (Colorado Ski and Golf, 2002).

Many of the Indo-Pacific islands, such as the Maldives and the Solomon Islands, are famous and popular destinations for dive tourism (Dive Discovery, 2002). Despite the strong geographic linkage with island surf tourism, however, there seems to be relatively little marketing crossover. Like surfing, diving has its own specialist magazines and tour operators. Certainly, there are surfers who are also divers, and vice versa. When it comes to spending money on an expensive island tour, however, perhaps most surfers would prefer two surf trips to one surf and one dive trip; and vice versa for divers.

One of the broad-scale social trends which has boosted adventure tourism over the past decade, is that people are tending to treat outdoor recreation more as a purchasable package holiday than as a lifetime skill (Buckley, 2000a). Both diving and surfing require a relatively high level of specialist skill, particularly in the conditions that apply in more remote areas such as many of the Indo-Pacific islands. Both diving and surfing, however, along with many other types of outdoor sport and adventure recreation, are becoming much easier to learn, with single-day introductory training courses now offered for each (Dive Discovery, 2002; Surfing Australia, 2002). At the same time, the growth in competitions, magazines and media programs which feature multiple adventure sports, may 
well be increasing the degree of crossover between the various adventure tourism activities in future.

\section{Social constructs and conflicts in surfing}

To a specialist tour operator, surfing may be an adventure tourism activity; but to different surfers, surfing is a competitive sport, a professional career, a recreational activity, a lifestyle, and/or an obsession. These perceptions are significant for surf tourism because surf tourists are surfers first and tourists second, so social constructs within the surfing community affect how surfers behave within the tourism industry (author, pers. obs., 1991-2002).

At a crowded surf break, many surfers are waiting for each wave, but ultimately only one can ride it. Which individual surfer takes each individual wave is determined not purely by overall skill, but by split-second decisions regulated by a strong behavioural code which determines priority (author, pers. obs., 19912002; Bartholomew, 1996; Young, 1994). Without this priority code, nobody would get any good rides, and many people would probably be injured. Associated with this basic wave-priority code, which is strongly and widely held by nearly all surfers worldwide, there are various additional codes, fashions and social pressures which are less widespread, and sometimes contentious. Some of these codes are especially relevant for Indo-Pacific island tourism.

In particular, individual surfers disagree strongly as to whether commercial entities should be able to purchase access rights to particular surf breaks, and exclude other surfers (English, 2002). This is of considerable practical significance for surf tourism. Currently, most easily accessible surf breaks are crowded, and most uncrowded surf breaks are inaccessible. To provide both rapid access and uncrowded conditions, a surf tour operator needs to be able to restrict numbers by some mechanism, either direct or indirect. If such restrictions are perceived as contrary to surfing ethics, however, this may restrict the operator's ability to maintain a supply of clients. This is hence a marketing issue rather than a legal one: the question is not so much whether the tour operator actually has the right, within local statutory or customary law, to restrict access; but more critically, whether such a restriction has negative repercussions amongst the broader surfing community which make up their clientele (Buckley, 2000b). It, therefore, becomes important for the surf tourism industry whether a creed of open access to all surf breaks by all surfers is seen as a fundamental tenet similar to the wave-priority code; or whether it is seen as a local variable which has to be ascertained at each break, with some breaks being open-access and others restrictedaccess.

The open-access issue is not restricted to commercial surf tourism. There are individual surf breaks in developed countries where surf magazines consistently report a particularly high degree of local aggression to visiting surfers, to the extent where it may be physically unsafe to surf there without an introduction from a local. Well-known locals are commonly accorded particular privileges at all surf breaks, however, so a break with access for local surfers only may be seen simply as an extension of this. It may also be seen as an internal issue between surfers, not related to money. Besides, superstrong localism is tolerated perforce by travelling surfers, rather than accepted willingly (author, pers. obs., 19912002). 
General access to particular surf breaks is commonly also restricted during surfing competitions, and this also causes conflict, particularly if the break concerned is the best in the vicinity, or the competition takes place during a period of particularly good surf. Competition organisers commonly have to obtain a permit from local authorities such as municipal councils or traditional owners, and they use these as an excuse to police the water and drive away other surfers during a competition. This only works, however, because surfers in general recognise the significance of competitions, admire the professional surfers who are competing, and want to see them perform. Hence individual surfers who paddle into a contest zone during a competition are not merely defying a local authority, which might not concern them, but also risking opprobrium from their fellow surfers, many of whom are probably watching the competition (author, pers. obs., 1991-2002).

Surfers who have visited Indo-Pacific island nations will also have learnt that in most of these countries, unlike the mainland surfing nations where nearshore waters are managed by a central government authority, individual reefs and beaches are commonly owned by the nearest village. The villagers are used to having exclusive access for fishing, and this approach commonly carries over to other boats, including those carrying surfers (author pers. obs. Solomon Is, 1998, Samoa 2001; Fiji Surf, 2000).

When commercial tourism entrepreneurs take paying surfers on charter boats or oceanfront lodges in Indo-Pacific islands, therefore, there is necessarily an interaction between at least four different cultures: the commercial and competitive ethic of the tour operator; the desires and codes of the individual surfers; the traditional and modern perspectives of local residents; and the requirements of government officials, formal or otherwise. It is these interactions, as much as the design of tour packages and the technologies used, which influence the role of surf tourism in sustainable development of Indo-Pacific island economies.

\section{Sustainable Development and Surf Tourism in Indo-Pacific Islands}

\section{Tourism in developing nations}

Tourism is becoming an increasingly important component in the economies of many developing nations, but not without controversy (Hall \& Lew, 1999; Honey, 1999; Mowforth \& Munt, 1998; Stabler, 1997). In particular, some developing nations have promoted themselves as international tourism destinations as a means of attracting foreign investment and incoming cashflow. The shape and path of tourism development has differed considerably between countries, depending not only on their natural attractions, but also on accessibility, infrastructure, government policies, and market moves by major international tourism operators. Very broadly, for example, the Caribbean has become known for its coastal resorts, and east and southern Africa for their wildlife. South-east Asia, Australia and Latin America are known for a combination of natural, cultural and adventure activities.

Tourism growth in these nations has indeed increased economic, entrepreneurial and employment opportunities. It has both social and environmental costs: but less so in practice, perhaps, than many other industry sectors. Social costs (Honey, 1999; Mowforth \& Munt, 1998; Robinson, 2000) may include: disruption 
of traditional cultural activities, social structures and subsistence economies; increasing inequities between individuals who profit directly from tourism and those who do not; and on occasion, forced relocation of entire communities. Social benefits may include improved education and health facilities, infrastructure and economic opportunities, as well as employment. Environmental costs may include direct impacts such as vegetation clearance and sewage discharge, and indirect impacts such as the introduction of weeds and pathogens, and increased poaching and collecting of rare plants and animals (Buckley, 2000b; Fennell, 1999; Harrison, 2000, McLaren, 1998; Newsome et al., 2002; Singh \& Singh, 1999; Weaver, 2001).

Many developing nations have seen substantial growth in adventure tourism, often coupled with nature and cultural tourism (Fennell, 1999). Nepal, for example, long known as a destination for high-altitude mountaineering, ice-climbing and trekking, is now also a major destination for whitewater rafting (Knowles \& Allardice, 1992) and wildlife viewing. India now offers Himalayan heliskiing and camel treks in Rajasthan, as well as the Taj Mahal and Red Fort, or low-budget beach tourism at Goa. Zimbabwe offers whitewater rafting on the Zambezi, and bungy jumping and heli tours over Victoria Falls, as well as wildlife safaris in its game parks; and Uganda offers rafting on the White Nile as well as one of the world's most exclusive wildlife viewing opportunities, the mountain gorillas of the Virunga. Pacific island resorts now promote themselves as active watersports destinations as well as places to laze in luxury, and Southeast Asian countries promote multisport ecochallenges as well as culture and cooking (Anon, 1999).

\section{Adventure tourism and small-island economies}

Small-island economies are very varied, but there are some recurring patterns, particularly for those in the Indo-Pacific region. The smaller and more remote islands generally have stronger subsistence economies, with a focus on smallscale agriculture and artisanal fisheries. Many rely heavily on international development assistance, both bilateral and multilateral, for infrastructure funding; and on remittances from family members overseas to fund private cash purchases such as consumer goods and travel (AIDAB, 1991,b; 1992a-d).

A few islands, such as Nauru, support a major mining industry, often the source of many remittances to other islands. Some of the smaller independent island nations have developed specialist industries in the finance, communications and information sectors. Tuvalu, for example, has for many decades generated significant income from the sale of postage stamps and first-day issues, and more recently has capitalised on the country code for its internet domain, which is ' $t v$ '. Other countries, such as Vanuatu in the Pacific or the British Virgin Islands in the Caribbean, have long been known for their offshore banking facilities and their advantageous corporate tax laws.

There are many other Indo-Pacific islands, however, particularly those which are part of large multi-island nations such as Indonesia, the Philippines or the Solomons, which are currently subject to intensive and highly unsustainable logging, with major environmental, social and economic impacts. In many instances the logging companies concerned are based in other nations, such as Japan and more recently Malaysia. Practices such as transfer pricing and the 
preferential and underpriced issue of logging licences to members of government and their relatives and friends seem to be widespread in some nations (Barraclough \& Ghimire, 1995; deBeer \& McDermott, 1989; Hurst, 1990; Kummer, 1992; Parnwell \& Bryant, 1996).

In some Indo-Pacific islands, there is also widespread land clearance for large-scale industrial agriculture, notably for oil palm, which is a major crop in many areas of Southeast Asia (McMorrow et al., 1996). Large-scale plantation agriculture to supply international commodities markets has a long history in Indo-Pacific islands. Many still support coconut plantations for copra, though these are not always well maintained. Others have been used historically for dry-climate crops such as sisal and wet-forest plantations such as rubber. Whilst most of these commodities have long since been replaced by substitutes for large-scale industrial consumption, some are currently enjoying a resurgence as specialist products. Coconut oil, for example, can now be produced in small quantities at high quality, and shipped rapidly for use in manufacturing boutique soaps and beauty products. This gives it a far higher value than formerly, when copra was collected by inter-island trading vessels at widelyspaced and erratic intervals. Such boutique products, however, currently have limited economic significance when compared to the ind ustrial oil palm plantations on the larger Pacific islands and adjacent Southeast Asian mainland.

Tourism is now a major economic sector for many islands worldwide, both in the Indo-Pacific region and elsewhere. Expedition cruise boats visit islands from Svalbard in the Arctic to South Georgia in the Antarctic, and throughout the temperate and tropical regions in between (Explorer Shipping, 2002). Almost all the larger Indo-Pacific islands have scheduled air services, and many of the smaller ones are accessible by local air services, float planes or ferries. Tourist hotels and resorts are widespread on the larger islands, and even smaller islands generally have some form of accommodation for visitors. In many cases this has arisen from customary systems for providing hospitality to visitors from other villages or islands. It is now commonplace for villages that are visited frequently by foreigners to have built small cabins or thatch-roofed sleeping platforms, known by different names in different countries, specifically for tourists (author, pers. obs., 1999-2001).

Tourist attractions and activities differ widely between islands, even within the Indo-Pacific region. Historically, the principal tourist marketing image was the South Seas island, portrayed as a romantic destination with golden sands, still blue seas, scattered palm trees, and abundant and exotic cocktails. Currently, however, islands are portrayed more often as adventure destinations with abundant opportunities for watersports, exotic scenery and cultural interactions. The volcanoes of Tannu and Mauna Loa are replacing the bars and beaches of Waikiki, in advertising imagery if not in economic significance. Large-scale beach resorts buy a few plastic sit-on-top sea kayaks and market themselves as a thrillseekers' paradise.

There is some fire behind this smoke, however, and in addition to repackaging old products, there has been real and rapid growth in adventure tourism worldwide, and particularly in the Asia-Pacific region where it was not previously a significant market sector. Africa, and to a lesser extent the Indian subcontinent, has a long tradition of game lodges and safaris and mountain climbing and 
trekking, and the recent growth in activities such as whitewater rafting represents a relatively small change. North America has a long tradition of outdoor recreation outfitters. The Andes have been known for climbing and trekking in the same way as the Himalayas, and the expansion to whalewatching, whitewater rafting, cultural tours and Amazonian ecotours has been gradual rather than abrupt. Southeast Asia, in contrast, has historically been marketed as a destination for duty-free shopping and golf, with a subsidiary historical theme (Hitchcock et al., 1993).

In recent years, however, a range of completely new Asian adventure tourism products have been offered, and marketing campaigns have sought to portray southeast Asia as a new adventure destination (Anon, 1999). There are a number of threads to this pattern. First is the proliferation of soft adventure opportunities aimed at backpackers and families with no particular specialist skills. These include, for instance, minibus tours and coastal watersports. This trend seems to be occurring worldwide. The second thread is that unlike their parents, younger generations from Southeast Asian nations are themselves taking to outdoor sports and adventure activities in increasing numbers. This parallels similar patterns in Latin America. For example, both Japanese and Brazilian surfers are now as numerous as Americans and Australians at well-known surf breaks throughout the Indo-Pacific region, and both nationalities are also represented in the professional surf competition circuit (ASP, 2002). The third major thread is the deliberate promotion of Asia-Pacific sites for international outdoor and adventure sports competitions, from windsurfing to whitewater, hang-gliding to multisports endurance racing (Anon, 1999).

Adventure tourism in general is hence increasing in economic significance worldwide, and particularly in the Asia-Pacific region. Surf tourism is a growing component of the adventure tourism sector, and Indo-Pacific islands offer some of the world's best surfing opportunities. For many small islands, surfing is no longer just an unusual and entertaining activity carried out by occasional and generally impecunious wandering foreigners, but a significant opportunity for economic growth. Even in larger islands, surf tourism can be the leading edge of the economically important nature, eco and adventure tourism (NEAT) sector.

\section{The environmental impacts of surf tourism on small islands}

For surf tourism on small islands, local environmental issues are likely to be more significant than contributions to global environmental issues. Global environmental issues for the sustainability of the tourism industry as a whole include: the environmental impacts associated with increased transport of material goods; those associated with the manufacture of consumer goods; and those associated with increased per capita consumption. As tourism contributes to global economic growth, it also contributes to global environmental degradation. In addition, tourism contributes specifically to global environmental deterioration through: the impacts of transporting tourists themselves; the impacts of manufacturing, packaging and transporting goods and consumables specifically to satisfy tourist preferences; and the impacts of increased resource consumption by people on holiday and away from their usual lifestyle routines. The contribution of surf tourism is probably similar, per person per day, to that of the tourism sector overall. 
For surf tourism on small islands, the most critical environmental issues are local rather than global. The principal exception is global sealevel rise, but this is beyond their control. Some of these local issues are specific to surf tourism, but many apply to island tourism in general, or indeed to any increased population on the islands concerned. As surf tourism becomes a significant economic activity on particular islands, it contributes correspondingly to these impacts. They include increased water consumption, pollution of drinking water supplies from waste dumps and landfills, and eutrophication of nearshore reefs and other marine ecosystems from sewage discharge (Brighughio et al., 1996; Buckley, 2000b; Carpenter \& Maragos, 1989; Harrison, 2000; Sweeting et al., 1999; WTO, 1999).

Water consumption and contamination are of particular concern in small sand islands and coral cays which rely on a groundwater lens for drinking water supplies. A groundwater lens is a body of fresh water, replenished by rainfall, which floats on top of seawater inside the sediments and sedimentary rocks of which the island is constructed (Dales, 1984). Because water can only percolate slowly through the sediments, the fresh water remains separate rather than mixing. If the rate of consumption exceeds the rate of replenishment, however, salt water can rise into the zone normally occupied by fresh water, so that ground water becomes brackish, affecting native vegetation as well as drinking water supplies. Since most reef islands are riddled below sea level with natural tunnels through coral rock, salinisation can occur quite quickly.

Tourism development typically increases the total number of people living on the island, concentrates them into smaller areas, and increases per capita water consumption considerably, since tourists want fresh water for showers, laundry, washing down equipment, etc. Tourism development on small reef islands can hence pose a significant risk that drinking water supplies may be contaminated by salt water. In the Maldives, for example, some islands which were previously used only intermittently by local residents now support year-round surf resorts which occupy the entire island (author pers. obs., 2002). These surf resorts are small compared to the mainstream resorts on other islands, but significant for the individual islands concerned.

Chemical and bacteriological contamination of drinking water is also an increasing risk on many small inhabited reef islands, where garbage is frequently dumped into a pit in the centre of a village and leaches directly into the freshwater lens. Traditional subsistence economies on these islands produced very little garbage, essentially all organic. On an island with tourist facilities, however, garbage typically includes batteries and containers contaminated with oils, solvents, detergents, pesticides and other potentially toxic compounds (Brodie \& Morrison, 1984).

Finally, water supplies, subsistence fisheries, and nearshore marine ecosystems can be contaminated with sewage and waste water, on reef islands as in coastal human habitation everywhere (Carpenter \& Maragos, 1989; Kato et al., 1985; Kimmerer \& Walsh, 1991; Lal, 1984).

Whilst reef islands are of particular significance for the surf tourism industry, most islands worldwide are rock. These range from small pinnacles to subcontinents, arctic to tropical, coastal to oceanic, barren to lush, uninhabited to densely populated. Some have sheer rock cliffs, some have beaches, some are surrounded 
by fringing reefs. For island surf tourism, the most significant are small to medium-size tropical and subtropical rock islands with fringing reefs. These can provide both high-quality surf breaks on the fringing reef, and tourism infrastructure and other attractions on the rock islands. Examples include Tahiti, Reunion, Samoa, and some of the islands in the Solomons, the Philippines, Fiji and Indonesia.

Many of these are in high-rainfall areas where water supplies are plentiful, at least at current population levels. Disposal of sewage and other wastes, often with little or no treatment, is a significant source of impact on fringing reef and other nearshore marine ecosystems. Many of the rock islands have towns or cities with urban infrastructure such as reticulated sewerage, municipal garbage collection services, and centralised sewage treatment and garbage landfill facilities. These, however, may still release nutrient-rich effluent and toxic leachates, and many are inadequate to service expanding shanty towns around the urban core.

One major difference between rock and reef islands used for surf tourism is that many of the rock islands support a rich flora and fauna which is under threat from other forms of industrial development, including agriculture, forestry and mining. If tourism can reduce the impacts of these industries, either by reducing the areas affected or by promoting more effective environmental regulation and environmental management, these environmental benefits could potentially outweigh the environmental costs of tourism itself. Tourism, including surf tourism, can therefore contribute to sustainable development in these islands by providing an economic and employment alternative to logging and large-scale plantation agriculture. In addition, at the scale of individual villages on both rock and reef islands, tourism can provide funds for education, health and disease control for local residents.

\section{Social impacts of surf tourism on small islands}

An economy dependent on tourism, whether at large or small scale, has its own costs and risks. It has environmental costs through increased resource consumption and waste production, both per capita and in aggregate. These may also have social costs, for example, where a particular resource is in short supply, and increased demand from tourism drives prices above the range affordable by local residents who are not involved in tourism.

Divisions and conflicts are commonplace in communities affected by tourism, particularly if a cultural framework which includes a responsibility for sharing wealth is replaced by a new culture of individual entrepreneurship (Mowforth \& Munt, 1998; Robinson, 2000; Stabler, 1999). Tourism also produces cultural impacts through commodification of traditional cultural activities, whether artistic, domestic or religious. And finally, a tourism-based economy is much more vulnerable to external fluctuations beyond the control of island residents (Milne, 1997).

For international surf tourism, cultural impacts can occur at several different levels. The first is when a particular destination, particularly in a developing country, becomes popular with travelling surfers from richer nations. As with most forms of tourism, some of the more entrepreneurial locals will take advantage of new commercial opportunities by providing tourist accommodation and 
local transport. These range from the very basic standards of the typical Indonesian losmen, built for itinerant surfers, to hotels on Australia's Gold Coast used by visiting surfers from Asian, American and European nations with strong currencies.

At this level, cultural impacts occur principally through an influx of money, and competition in the host community to see who can get most of it. Crowding and crime are the most common cultural impacts, bad for locals and visitors alike (Wall, 1997).

The second level occurs where foreign tour operators build up-market enclave-style tourist accommodation, where locals work as staff but can't afford to stay as guests. Typically this creates tension within the host community between those who will profit from real estate deals or plum jobs, and those who think it makes locals into second class citizens in their own home town, not to mention their own surf breaks. Once again, this effect can occur with exclusive clubs in Australia, California or Hawaii, just as much as surf resorts on Pacific Islands. And once again, this type of effect is certainly not exclusive to surf tourism.

The third kind of cultural impact, however, is very specific to surfing. Surfers are used to free access to surf breaks, except during competitions. To surfers from most countries it is a basic rule of surfing culture that anyone can get in the water. But these rules are part of a surfing culture which, though international, is derived from countries with a European history. On Pacific islands and in southeast Asia, the local cultures have a Polynesian, Melanesian or Micronesian background. Except in Hawaii, surfing is not part of their traditional culture, but fishing is. And because traditional economies relied heavily on subsistence fishing, every village controls access to nearby seas and reefs, whether waves are breaking on them or not. For foreigners to surf those reef breaks without permission, therefore, is certainly rude, possibly illegal under customary law, and a cultural impact in either case (Buckley, 2000b).

\section{Conclusions}

Commercial surf tourism is a new influence for Indo-Pacific islands. Part of a multibillion dollar global adventure tourism industry, it has the potential to overwhelm individual islands, or to provide them with a long-term source of income from a growing market sector. In the process it has the potential to create major cultural and environmental impacts; or to provide a key to development in the broader nature, eco and adventure tourism sector which can help to conserve both native plant and animal habitats, and traditional cultures. What happens in practice on particular islands depends on how those islands manage commercial surf tourism, as well as the broader context of overall development patterns in the region.

Surf tourism has received very little study to date, either practical or theoretical. Research, analysis and predition has not caught up with growth and changes in the industry itself. The aim of this overview has been to introduce the surf sector to tourism and development analysts and encourage documentation of case studies so that the significance of the sector many be better established. 


\section{Correspondence}

Any correspondence should be directed to Ralf Buckley, International Centre for Ecotourism Research, School of Environmental and Applied Sciences, Griffith University, PMB 50, Gold Coast Mail Centre Southport, QLD 9726, Australia 4217 (r.buckley@mailbox.gu.edu.au).

\section{References}

Amazing Fiji (2002) Nagigia surf resort. On WWW at www.fijisurf.com. Accessed 12.7.02. Anon (1999) A season of wind and waves. Action Asia 2 (8), 68-77.

Anon (2001) Quiksilver plans to surf for gold on Grafton Street. Sunday Business Post (9 September). Dublin.

Association of Surfing Professionals (2002) ASP world tour. On WWW at www. aspworldtour.com. Accessed 12.7.02.

Atoll Travel (2002) Atoll travel. On WWW at www.atolltravel.com. Accessed 15.7.02.

AIDAB (Australian International Development Assistance Bureau) (1991a) The Solomon Islands Economy: Prospects for Stabilisation and Sustainable Growth. Canberra: Australian Government Publishing Service.

AIDAB (1991b) The Western Samoan Economy: Prospects for Recovery and Long Term Growth. Canberra: Australian Government Publishing Service.

AIDAB (1992a)The Papua New Guinea Economy: Prospects for Recovery, Reform and Sustained Growth. Canberra: Australian Government Publishing Service.

AIDAB (1992b) The Economy of Fiji: Performance, Management and Prospects. Canberra: Australian Government Publishing Service.

AIDAB (1992c) The Tongan Economy: Setting the Stage for Accelerated Growth. Canberra: Australian Government Publishing Service.

AIDAB (1992d) The Kiribati Economy: Development Options and Prospects for Growth. Canberra: Australian Government Publishing Service.

Barraclough, S.L. and Ghimire, K.B. (1995) Forests and Livelihoods: The Social Dynamics of Deforestation in Developing Countries. London: Macmillan.

Bartholomew, W. (1996) Bustin' Down the Door. Pymble: Harper Collins.

Billabong (2002a) The odyssey. On WWW at www.billabongodyssey.com. Accessed 12.7.02.

Billabong (2002b) Billabong boost. On WWW at www.billabong.com/freewaytour. Accessed 12.7.02.

Billabong (2002c) Billabong girls. On WWW at www.billabonggirls.com. Accessed 12.7.02.

Brodie, J.E. and Morrison, R.J. (1984) The management and disposal of hazardous wastes in the Pacific Islands. Ambio 13,331-3.

Brighughio, L., Archer, B., Jafari, J. and Wall, G. (eds) (1996) Sustainable Tourism in Islands and Small States. London: Pinter.

Buckley R.C. (2000a) NEAT trends: Current issues in nature, eco and adventure tourism. International Journal of Tourism Research 2, 437-44.

Buckley, R.C. (2000b) Application of regulatory and voluntary instruments for sustainable tourism development in small islands. In H. Varma (ed.) Island Tourism in Asia and the Pacific (pp. 46-64). Madrid: World Tourism Organisation.

Carpenter, R.A. and Maragos, J.E. (1989) How to Assess Environmental Impacts on Tropical Islands and Coastal Areas. South Pacific Regional Environmental Programme, Asian Development Bank and East-West Center. Honolulu: Environmental and Policy Institute, East-West Center.

Colorado Ski and Golf Ltd. (2002) Welcome to Colorado's largest ski and snowboard retailer. www.onsaleonline/com/clients/csg/csg. Accessed 12.7.02.

Dales, W.R. (1984) A Bibliography of Hydrogeology of Small Islands. Wellington, New Zealand: Department of Scientific and Industrial Research. 
de Beer, J.H. and McDermott, M.J. (1989) The Economic Value of Non-Timber Forest Products in Southeast Asia and Special Emphasis on Indonesia, Malaysia and Thailand. Amsterdam: IUCN.

Dive Discovery (2002) Solomons. On WWW at www.divediscovery.com/solomons. Accessed 12.7.02.

English, B. (2002) Surfing on the crest of an island's poverty. Daily Telegraph (22 June), 39.

Explorer Shipping (2002) Explorer. On WWW at www.explorership.com. Accessed 15.7.02.

Extreme Sports Maui (2002) On WWW at www.maui.net/extreme/homenew. Accessed12.7.02.

Fennell, D.A. (1999) Ecotourism: An Introduction. London: Routledge.

Fiji Escapes (2002) Namotu Island surf resort - Fiji Islands. On WWW at www.fiji-islands. $\mathrm{com} /$ namotu. Accessed 12.7.02.

Fiji Surf (2002) Tui Ta-Tevita Koroi. Notice to surfers. On WWW at www.fiji-surf.com/ chief. Posted November 2000. Accessed 12.7.02.

Google Inc. (2002) Directory. On WWW at google.com/Top/Sports/Water_Sports/ Surfing/News_and_Media. Accessed 12.702.

Go Tours (2002) Go Tours Travel: Surf the earth. On WWW at www.gotours.com.au. Accessed 15.7.02.

Great Breaks International (2002) Mentawai ecofriendly surfing, trekking, diving and sailing. On WWW at www.mentawai.com. Accessed 12.7.02.

Ha'atafu Beach Resort (2002) Ha'atafu Beach Resort. On WWW at www.surfingtonga. com. Accessed 12.7.2002.

Hall, M. and Lew, A. (eds) (1999) Sustainable Tourism: A Geographical Perspective. London: Longman.

Harrison, D. (2000) Tourism's impacts on island environments: Towards a framework for decision-making. In H. Varma (ed.) Island Tourism in Asia and the Pacific (pp. 65-77). Madrid: World Tourism Organisation.

Hitchcock, M., King, V.T. and Parnell, M.J.G. (eds) (1993) Tourism in South-East Asia. London: Routledge.

Honey, M. (1999) Ecotourism and Sustainable Development: Who Owns Paradise? Washington, DC: Island Press.

Hurst, P. (1990) Rainforest Politics: Ecological Destruction in South-East Asia. London: Zed Books.

Hynd, D. (1991) The history of the humble surfboard. Waves (Jul/Aug), 72-9.

Indies Trader (2002) Indies Trader marine adventures. On WWW at www.indiestrader. com. Accessed 15.7.02.

Kato, I., Kumamoto, N., Mathews, W.H. and Suhaimi, A. (1985) Environmental Protection and Coastal Zone Management in Asia and the Pacific. Tokyo: University of Tokyo Press.

Kimmerer, W.J. and Walsh, T.W. (1991) Tarawa atoll lagoon: Circulation, nutrient fluxes, and the impact of human waste. Micronesia 17, 161-79.

Knowles, P. and Allardice, D. (1992) White Water Nepal. Surrey, UK: Rivers Publishing.

Kummer, D.M. (1992) Deforestation in the Postwar Philippines. Manila: Ateneo de Manila University Press.

Lal, P.N. (1984) Environmental implications of coastal development in Fiji. Ambio 13,31621.

McLaren, D. (1998) Rethinking Tourism and Travel. Connecticut: Kumarian Press.

McMorrow, J.M., Mustapa, T. and Lawes, H. (1996) Monitoring tropical rainforest conservation to estate agriculture in Sabah, Malaysia, using Landsat images and GIS. In H.A. Hassan, Y.M. Chin and R. Nasarruddin (eds) Multiple Resource Inventory and Monitoring of Tropical Forests (pp. 228-44). Kuala Lumpur: ASEAN Institute of Forest Management (AIFM).

McKnight, R. (2002) Letter to shareholders, in Annual Report. On WWW at www. quiksilver.com. Accessed 12.7.02.

Milne, S. (1997) Tourism, dependency and South Pacific microstates: Beyond the vicious cycle. In G. Shaw and A. Williams (eds) Island Tourism (pp. 281-301). London: Pinter. 
Mowforth, M. and Munt, I. (1998) Tourism and Sustainability: New Tourism in the Third World. London: Routledge.

Newsome, D., Moore, S. and Dowling, R. (2002)Natural Areas Tourism: Ecology, Impacts and Management. Clevedon, UK: Channel View.

Otuhaka Beach Resort (2002) Otuhaka Beach Resort, Kingdom of Tonga. On WWW at www.tongaholiday.com/otuhaka. Accessed 12.7.02.

Parnwell, M.J.G. and Bryant, R.L. (eds) (1996) Environmental Change in South-East Asia: People, Politics and Sustainable Development. London: Routledge.

Quiksilver (2002) On WWW at www.quiksilver.com. Accessed 12.7.02.

Raymond, B. (1998) Untitled. Australian Surfers Journal (Summer).

Rip Curl (2002) On WWW at www.ripcurl.com. Accessed 12.7.02.

Robinson, J. (2000) Socio-cultural dimensions of sustainable tourism development achieving the vision. In H. Varma (ed.) Island Tourism in Asia and the Pacific (pp. 78-86), Madrid: World Tourism Organisation.

Salani Surf Resort (2002) Welcome to Salani Surf Resort. On WWW at www.surfsamoa. com. Accessed 12.7.02.

Sa'moana Resort (2002) Sa'moana Resort. On WWW at www.samoanaresort.com. Accessed 12.7.02.

Singh, T.V. and Singh, S. (eds) (1999) Tourism Development in Critical Environments. New York: Cognizant.

South East Asia Liveaboards (2002) Surfing in India (the Andaman Islands). On WWW at www.seal-asia.com/surfing. Accessed 12.7.02.

Surfaris (2002) Welcome to Surfaris. On WWW at www.surfaris.com. Accessed 12.7.02.

Surfing Australia (2002) Surf schools. On WWW at www.surfingaustralia.com.au. Accessed 12.7.02.

Surf History (2002) On WWW at www.surfhistory.com. Accessed 12.7.02.

Surf Info (2002) Surf tour companies. On WWW at www.surfinfo.com.au/index. Accessed 12.7.02.

Surf Travel Company (2002) Surf Travel Co. On WWW at www.surftravel.com.au. Accessed 12.7.02.

Stabler, M.J. (ed.) (1997) Tourism and Sustainability: Principles to Practice. New York \& Wallingford: CAB International.

Stone, J. (2000) Advertisements in surfing magazines. Unpublished report, Griffith University, Gold Coast, Australia.

Swatch (2002) Pro Team. On WWW at www.swatch.com/sportszone. Accessed 12.7.02.

Sweeting, J.E.N., Bruner, A.G. and Rosenfelt, A.B. (1999) The Green Host Effect: An Integrated Approach to Sustainable Tourism and Resort Development. Washington, DC: Conservation International.

Telski Ltd (2002) On WWW at www.tellurideskiresort.com/golf. Accessed 12.7.02.

Trent, J. (2000) Ready to wear. Surfer Girl 2 (2), 34. Published as part of Surfer 41 (8).

Wall, G. (1997) Bali and Lombok: Adjacent islands with contrasting tourism experiences. In G. Shaw and A. Williams (eds) Island Tourism (pp. 268-80). London, Pinter.

Wannasurf (2002) La Reunion. On WWW at www.wannasurf.com/sport/africa/ Reunion-Island. Accessed 12.7.02.

Waves Surf School (2002) On WWW at www.wavessurfschool.com.au. Accessed 12.7.02.

Weaver, D. (ed.) (2001) Encyclopaedia of Ecotourism. Wallingford: CAB International.

World Surfaris (2002) On WWW at www.worldsurfaris.com. Accessed 15.7.02.

World Tourism Organisation (1999) Guidelines for Local Authorities on Developing Sustainable Tourism: Supplementary Volume, Asia and the Pacific. Madrid: WTO.

Young, N. (1994) The History of Surfing. Palm Beach: Palm Beach Press.

\section{Personal Communications}

R. Cameron owns and works for Great Breaks International

J. Stone is at Griffith University

N. Hyman owns and works for Nev's Future Shapes

P. Blanche owns and works for Go Tours. 